5286 men are presented. External data and older internal data are also presented as a comparison.

Results $56 \%$ of the men were under 45 years old and $44 \%$ were between 45 and 65 years old. Sufficient numbers of employees from the building construction, civil engineering and interior construction sectors took part in the survey. Approx. 30\% have management responsibilities. Of the 16 stresses participants were asked about, the most common by order of occurrence: intense concentration, tension (52\%), high responsibility $(56 \%)$ and time or deadline pressure, rushing (61\%). 28\% described their overall health as excellent or very good, with a significant age discrepancy $(\leq 24: 54 \%$; $\geq 55$ : 9\%). 19\%/14\% reported that they accomplished less at work or in everyday tasks due to their physical or mental health.

Discussion The results show that in addition to familiar physical stresses like dust, noise and lifting and carrying heavy loads, construction work also involves mental strains that are not sufficiently recognised. Accordingly, this is not sufficiently prioritised in prevention measures in practice, also due to the complexity of the subject matter. The results offer sector-specific arguments and will help provide focused advice to employees and entrepreneurs by company doctors.

\section{MENTAL HEALTH MORBIDITY AMONG MEDICAL AND SURGICAL ONCOLOGY RESIDENTS}

A Fahim*, A Waheed, H Aly. Department of Community, Environment and Occupational Medicine, Faculty of Medicine, Suez Canal University, Ismailia, Egypt

\subsection{6/oemed-2018-ICOHabstracts. 1673}

Introduction Oncology clinicians represent stressful occupational category and suffer mental health morbidity. They are exposed to the clinical stressors and emotional demands related to care of cancer patients and their families, and feel worried about their career future. The present study was conducted to assess some aspects of mental health among medical and surgical oncology residents.

Methods This survey was conducted to assess some mental health aspects among residents, who have at least 1 year of work experience at both medical and surgical oncology departments. All participants were asked to complete a questionnaire. The questionnaire was based on items that included General Health Questionnaire (GHQ-12) to assess psychological distress; Symptom Checklist for Depression (SCD) to measure depression; and questions about demographic and occupational data. Logistic regression was used to assess the association between potential predictor variables of GHQ and SCD, results were considered statistically significant when $\mathrm{p}$ value less than 0.05

Results Thirty seven physicians responded (response rate 91.3\%). Levels of psychological distress and depression were measured by GHQ and SCD. Eleven physicians (29.7\%, 95\% CI; 17.3-45.7) scored $>3$ on GHQ indicating psychological distress, and $37.8 \%$ (95\% CI: 24.1 to 53.9 ) scored $\geq 1.5$ on SCD indicative of depression. Suicidal thoughts were reported by 3 residents. The effect of occupational stress was the main predictor of both psychological distress and depression.

Conclusion Stress needs to be managed among physicians in such specialties to have a satisfactory professional life and high job productivity.
767

HEALTHY ENTERPRISE STANDARD (HES) EVALUATION: ANALYSING EFFECTS AND COST-BENEFIT RESULTS WITH A QUALITATIVE EVALUATION OF IMPLEMENTATION PROCESS

${ }^{1} \mathrm{H}$ Sultan-Taïeb, ${ }^{2} \mathrm{~F}$ St-Hilaire, ${ }^{3} \mathrm{~A}$ Gaillard, ${ }^{2} \mathrm{R}$ Lefebvre, ${ }^{4} \mathrm{C}$ Duchaine, ${ }^{4,5} \mathrm{~K}$ Aubé, ${ }^{4,5} \mathrm{M}$ $\mathrm{C}$ Letellier, ${ }^{4,5} \mathrm{C}$ Brisson, ${ }^{6} \mathrm{M}$ Vézina, ${ }^{5} \mathrm{C}$ Biron, ${ }^{6} \mathrm{M}-\mathrm{M}$ Mantha-Bélisle. ${ }^{1}$ École des Sciences de la Gestion, Université du Québec à Montréal (UQAM), Montréal, Canada; ${ }^{2}$ Management School, Université de Sherbrooke, Sherbrooke, Canada; ${ }^{3}$ Université de Bourgogne, France; ${ }^{4} \mathrm{CHU}$ de Québec Research Centre, Population Health and Optimal Health Practices Unit, Quebec City, Canada; ${ }^{5}$ Laval University, Quebec City, Canada; ${ }^{6}$ Institut National de Santé Publique du Québec, Quebec City, Canada

\subsection{6/oemed-2018-ICOHabstracts. 1674}

Introduction The Healthy Enterprise Standard (HES) is related to a certification program in Québec (Canada) and targets four areas: Lifestyle, Work-life balance, Workplace environment and Management practices. The aim of this study was to open the black box of intervention and analyse the implementation process in order to interpret effects of HES on health and workplace risk factors, and cost-benefit results from the employer's perspective.

Methods We used a before-after design for a two-case analysis with a mixed-method approach. In two organisations from different sectors, quantitative data were collected with a questionnaire among all active workers before the standard's implementation ( $\mathrm{T} 1$ organisation $\mathrm{A}=186$, organisation $\mathrm{B}=1081)$ and $25-31$ months after (T2 $\mathrm{A}=190, \mathrm{~B}=975)$. Psychosocial work factors (demand-control-support and effortreward imbalance validated scales), psychological distress (validated Kessler-6), and work-related musculoskeletal problems (WMSP, 4 items from the Nordic Questionnaire) were measured as well as intervention exposure. Intervention costs data, presenteeism and absences data were collected. Qualitative data through interviews and focus groups in both organisations were recorded, transcribed and coded in order to perform thematic analysis a posteriori.

Results The prevalence of psychosocial work factors (low social support, low reward) at T2 was lower amongst participants exposed to intervention in the Management practices area in both organisations. WMSP was lower for those exposed to the Workplace environment area in $\mathrm{B}$. The average cost per worker per year was very similar for A and B whereas distribution of cost categories differed. The net benefit was highly positive in B and negative in A. Implementation analysis showed that each area of HES was associated to different types of facilitators and obstacles. Cyclical factors, communication and management involvement differed between A and $\mathrm{B}$.

Discussion These results show that the implementation process analysis provides interesting insights into understanding effect and cost-benefit results and improving OSH interventions.

\section{A COMPARATIVE EUROPEAN ANALYSIS OF THE LINK BETWEEN WORK STRESSORS AND WORKER OUTCOMES}

${ }^{1,2}$ Dorothy Watson* ${ }^{1,2}$ Helen Russell, ${ }^{1,2}$ Bertrand Maitre, ${ }^{1,2}$ Oona Kenny. ${ }^{1}$ Economic and Social Research Institute, Dublin, Ireland; ${ }^{2}$ Trinity College Dublin, Ireland

\subsection{6/oemed-2018-ICOHabstracts. 1675}

Introduction Given the changing nature of employment, including the long term shift from manufacturing and agriculture to the service sector, an increasing proportion of the 